\title{
"CLÁUSULA DE BARREIRA" COMO RESPOSTA À CRISE DO SISTEMA POLÍTICO NO BRASIL: LIMITES E POSSIBILIDADES
}

\section{"BARRIER CLAUSE" AS A RESPONSE TO THE CRISIS OF THE POLITICAL SYSTEM IN BRAZIL: LIMITS AND POSSIBILITIES}

\author{
${ }^{1}$ Ricardo Silveira Castro
}

\section{RESUMO}

No debate a respeito da crise de representatividade enfrentada pelo sistema político brasileiro, a reflexão sobre a limitação da forma de atuação dos partidos políticos merece destaque. $\mathrm{O}$ presente trabalho tem o objetivo de, a partir da retomada histórica da posição da "cláusula de barreira" no ordenamento jurídico pátrio, avaliar o potencial desse mecanismo enquanto resposta à crise de representatividade experimentada pela democracia brasileira. A ênfase da avaliação crítica recairá especificamente sobre a PEC36/2016, atualmente em trâmite no Senado, quanto à promessa de combater a fragmentação política que prejudica o sistema brasileiro presidencialista de coalisão.

PALAVRAS-CHAVE: Democracia; Partidos Políticos; Crise; Cláusula de Barreira; Sistema político

\begin{abstract}
In the debate about representativeness' crisis faced by the Brazilian political system, the reflection on the limitation of the political parties' way of acting deserves to be highlighted. The present work has the objective of evaluating the potential of this mechanism as a response to the representativeness' crisis experienced by Brazilian democracy, based on the historical recovery of the position of the "barrier clause" in the legal order of the country. The critical evaluation' emphasis will be specifically on the PEC36/2016, currently under way in the Senate, on the promise to combat the political fragmentation that undermines the Brazilian presidentialist coalition.
\end{abstract}

KEY WORDS: Democracy; Political Parties; Crisis; Barrier clause; Political System

\footnotetext{
${ }^{1}$ Mestrando Em Direito Pela Universidade Federal do Rio Grande do Sul - UFRGS, Rio Grande do Sul, RS, (Brasil). Advogado. E-mail: silveiraricardocastro@gmail.com.
} 


\section{INTRODUÇÃO}

A incapacidade das organizações partidárias em representar efetivamente os setores sociais articulados ao redor de projetos politica, econômica, cultural e ideologicamente orientados já é, na prática, uma verdade comumente aceita no cenário sociopolítico brasileiro. As próprias manifestações que ganharam os espaços públicos em junho de 2013 expressam de modo significativo o grau de desconfiança da sociedade civil para com este instrumento que, pela Constituição Federal vigente, é indispensável na estruturação do funcionamento democrático no Estado de Direito fundado em outubro de 1988.

Diante do papel entregue aos partidos políticos no sistema de democracia representativa brasileira, a crise envolvendo a legitimidade de suas funções repercute de modo direto no núcleo basilar do sistema político: como contornar a ineficácia do único mecanismo de organização da representação, sem o qual a própria base do sistema político constitucionalmente desenhado não teria condições de se manter? É justamente a partir da identificação desse problema que, inicialmente, o presente trabalho reconstituirá os debates havidos no campo da Ciência Política a respeito do delineamento conceitual da organização partidária e das divergências relativamente às funções a serem desempenhadas por elas.

Após a identificação desses debates teóricos, na segunda parte do estudo, partir-se-á para a demarcação da proposta que emerge no cenário político pátrio como potencialmente capaz de responder à situação de instabilidade e crise na arena do sistema político: a implementação de "cláusula de barreira" que seja capaz de qualificar a atuação das organizações partidárias, em real alinhamento com as demandas do eleitorado. Essa parte do trabalho está dividida em duas principais seções: inicialmente, verificar-se-á o histórico do referido mecanismo ("cláusula de barreira") no ordenamento jurídico pátrio, com o fim de subsidiar uma análise dos contextos históricos em que tal instrumento foi veiculado por nosso sistema, bem como para definir o seu pretenso potencial; na sequência, buscar-se-á analisar criticamente a proposta de emenda constitucional número 36, de 2016, que está tramitando no Senado Federal e tem como um de seus objetivos principais a implementação de "cláusula de barreira" ao sistema político brasileiro.

\section{PARTIDOS POLÍTICOS E DEMOCRACIA: AS RELAÇÕES POSSÍVEIS}


Inicialmente, antes de avaliar os argumentos que negam, de um lado, e que afirmam, de outro, a utilidade da "cláusula de barreira" como ferramenta de combate à crise do sistema político brasileiro, buscar-se-á ampliar os horizontes analíticos com a imersão no debate contemporâneo travado no âmbito da Ciência Política a respeito das origens e das funções dos partidos políticos. Em um primeiro momento, estabelece-se um panorama geral das divergências teóricas que rivalizam na explicação das origens do fenômeno partidário - com demonstração das delimitações dos reflexos dessa discussão na elaboração de diferentes “conceitos" para o mesmo fenômeno. Logo em seguida, parte-se para a demarcação das funções exercidas pelos partidos nos regimes democráticos e a delimitação do problema de fundo que repercute diretamente na crise dos sistemas políticos multipartidários, em geral, e brasileiro, em particular: a legitimidade do exercício do poder político

É importante destacar que, na seara dos estudos em Ciência Política, não há consenso a respeito da delimitação conceitual do fenômeno partido político. Aliás, "definir conceptos es, em ciências sociales, un problema gordo" (GONZÁLEZ, 2009). Especificamente no caso dos partidos políticos, três principais dificuldades se impõem diante dos teóricos: a primeira diz respeito ao fato de que os partidos não são o mesmo em todo tempo e lugar ${ }^{2}$; a segunda está vinculada com a ausência de consenso nos debates acadêmicos sobre as funções desse mecanismo (Promover o interesse nacional - público - ou controlar o aparato de governo?); a terceira está associada às duas primeiras e revela-se como empecilho à maioria dos projetos de classificação e de definição conceitual, qual seja, a articulação de categorias úteis - isto é que possuam significativo grau de rigor (coerência) e de exatidão.

O debate travado entre Angelo Panebianco e Leon Epstein ilustra de modo bastante claro o contexto de divergências teóricas existente nessa seara: enquanto o primeiro parte da pressuposição de que os partidos políticos são antes de tudo organizações - isto é - estruturas estáveis, que não se confundem com os indivíduo que a compõem (a ênfase conceitual está na própria estrutura do partido), o segundo afirma que os partidos são quaisquer grupos, mesmo pouco organizados, que busquem espaço na estrutura do governo (como se pode perceber, nesse caso, a ênfase conceitual está na função exercida por esse ator do sistema político). Particularmente quanto as dificuldades dos teóricos sobre essa questão - qual a(s) função(ões) exercida(s) pelos partido políticos nos regimes democráticos? - interessa-nos vinculá-las com o desafio de conceituar o próprio fenômeno partidário já que, como fica claro na obra de

\footnotetext{
2 "El concepto partido político es, pues, un concepto polissêmico condicionado por su impronta geográfica, histórica y evolutiva" (GONZÁLEZ, 2009).
} 
diversos autores a serem destacados na sequencia, ambas questões se confundem durante o discurso teórico elaborado.

A dificuldade em delimitar o conceito de partido político levou Kay Lawson a mapear cinco diferentes critérios para estabelecer cinco contornos coerentes: o histórico, o estrutural, o de comportamento, o funcional-sistêmico e o ideológico. A partir disso, a pluralidade de conceitos deixa de ser um problema, na medida em que o debate se desloca para a perspectiva analítica que predetermina sua forma. Nesse sentido, desde o debate da obra de Lawson (que data da segunda metade do século XX) emergem quatro principais critérios (ou perspectivas) que definem os contornos dos partidos políticos. O primeiro, chamado de "organizativo", concebe o partido como "una estrutura que responde y se adapta a una multiplicidad de demandas por parte de sus distintos julgadores y que trata de mantener el equilíbrio conciliando aquellas demandas" (PANEBIANCO, 1990, p.36). O segundo, denominado de "ideológico", afirma que "los partidos son sobre todo organizaciones ideológicas que se han estabilizado a lo largo de conflitos diversos sobre el dogma” (BEYME, 1986, p.35). O terceiro, conhecido como "funcionalista", delimita que "los partidos son cualquier grupo político que se presenta a elecciones y que puede colocar mediante elecciones a sus candidatos a cargos públicos" (SARTORI, 1980, p.92). Por fim, a perspectiva da "eleição racional" define partidos políticos "como fracciones de políticos sin ninguna estrutura organizativa", com acento "a las ambiciones individuales de quienes lo conforman" (KREHBIEL, 1993, p.1-2).

O presente estudo não tem o objetivo de elencar todas as construções teóricas a respeito da definição conceitual do fenômeno partidário, nem a de apontar aquela que melhor cumpre o papel de explica-lo coerentemente. A demonstração da divergência presente na Ciência Política nesse ponto é importante para uma importante constatação: muitas questões a respeito da definição e das funções exercitáveis pelos partidos políticas ainda estão em aberto, sem respostas definitivas. Duas premissas, entretanto, podem ser afirmadas com base na observação histórica do fenômeno partidário: os partidos políticos são um fenômeno contemporâneo - mais precisamente, "em el sentido moderno de la palavra no existen antes de 1850" (DUVERGER, 1957, p.15); e, ainda, o surgimento dos partidos políticos está diretamente vinculado à estruturação democrática dos Estados, de tal forma que se afirmou serem os partidos políticos "hijos de la democracia, del derecho - aprontado la víspera del siglo XX - de las masas al sufrágio" (WEBER, 1967, p.128). O sentido de partido político classificado acima como "moderno" se contrapõe aos clubes e associações do século XVIII, e 
retira o seu ineditismo pela reunião de quatro características essenciais: "una organización permanente no sujeta a la muerte del fundador; una estrutura que conecte unidades nacionales y locales; una determinación de ejercer el poder; una voluntad de mantener el poder mediante el apoyo de militantes y electores (LAPALOMBARA; WEINER, 1966, p.6).

A afirmação da indissociabilidade entre partidos políticos e democracia tem como base o fato de que os partidos nascem em regimes democráticos representativos, com o fim de organizar a inclusão das massas (historicamente excluídas dos processos de tomada de decisão política) no sistema de participação. O centro dos primeiros estudos a respeito do fenômeno partidário é justamente os partidos socialistas que emergem na Europa do século XX como resultado da implementação do sufrágio universal. Nesse sentido, os "partidos de massa" (DUVERGER, 1957) ingressam no sistema para cumprir a função de integrar (formalmente) os grupos marginalizados pelo sistema político, na medida em que representam a possibilidade desses setores ingressarem no processo de decisão política. Na teoria clássica dos partidos políticos, os partidos de massa - de origem extraparlamentar (com vínculo direto aos movimentos sociais de operariados e aos sindicatos) - disputam no cenário público com os "partidos de quadro" (DUVERGER, 1957), isto é, aqueles organizados dentro da própria estrutura institucional (parlamento) para dar sustentação aos interesses dos setores que sempre conduziram o sistema político (comumente associados às elites).

No âmbito teórico, o principal contraponto foi suscitado por Robert Michels diante da realidade concreta alemã no início do século $\mathrm{XX}$, quando a tendência de oligarquização dos partidos políticos foi afirmada de modo claro pela primeira vez. A lógica segundo a qual democracia pressupõe organização capaz de instrumentalizar a vontade da coletividade - isto é - resultaria na necessidade de composição de órgãos representativos e, estes, por sua vez, estariam fadados a distorcer o interesse do povo. Nesse aspecto, haveria um ciclo natural percorrido por todo o poder: emanado do povo, acaba por se colocar acima do povo - isto é, "representar é fazer aceitar como sendo vontade da massa aquilo que não é senão vontade individual" (MICHELS, 1962, p.16). Ao avaliar o caso particular do partido socialista alemão, Michels conclui que em função do desinteresse das massas nos processos de tomada de decisão, invariavelmente a organização dos grupos partidários importaria na formação de “elites" dentro do sistema de representação. A indispensável estabilidade dos líderes políticos - para que estes pudessem dar sequência ao conjunto de ações políticas destinadas ao alcance dos objetivos partidários - tem como pressuposto básico a centralização da estrutura partidária. O rompimento desta construção teórica com diversas premissas do pensamento 
democrático do século XX tem impacto direto no debate a respeito do papel dos partidos políticos nos regimes democráticos, com o ineditismo de - a partir da análise de um caso concreto (a realidade do Partido Social-Democrata Alemão) - afirmar a existência de uma tendência conservadora inerente a toda forma de organização social, verificável inclusive em experiências autodeclaradas como "socialistas".

A perspectiva micheliana altera de modo substancial a construção clássica que vinculava partidos políticos e democracia como conceitos intimamente associados a uma realidade prática verificável e inquestionável. É importante destacar que a crítica de Michels não se esgota na desconstrução das funções democráticas dos partidos políticos (com a articulação da "lei de ferro da oligarquia"), estendendo-se ao enfrentamento da viabilidade prática das promessas realizadas pelos regimes democráticos. Nesse sentido, ao afirmar que a democracia cria o seu próprio inimigo - já que a imprescindibilidade de mecanismos capazes de darem respostas rápidas e imediatas a problemas e impasses do cotidiano sociopolítico de todas as comunidades não se ajusta à lentidão das assembleias populares - Michels está questionando a própria viabilidade dos regimes democráticos. De qualquer modo, no enfoque do presente estudo deixaremos de lado as problematizações envolvendo essa questão teórica mais abrangente para destacar a conclusão de recorte mais específico a que chega o referido autor: os partidos políticos estão condicionados por uma lei incontornável do sistema político como um todo, qual seja, a de que a oligarquia representa uma forma preestabelecida da vida em comum dos grandes agregados sociais.

Na linha de enfrentamento dos pressupostos teóricos articulados por Michels, o debate a respeito do condicionamento da atuação dos partidos políticos ganhou o espaço acadêmico. As principais articulações de combate à perspectiva micheliana reuniram seus argumentos ao redor de uma base em comum: a temporalidade da "lei de ferro" de Michels. Nesse sentido, o fenômeno observado por Michels seria efeito de alterações importantes ocorrida do sistema político representativo de seu tempo, com marcas muito particulares. O século XX traz para o cenário político a complexidade decorrente da adoção, pela maioria dos ordenamentos jurídicos europeus, do sufrágio universal. A ascensão de partidos socialistas e a ameaça representada pela participação das massas populares que ingressam formalmente no processo político provocam uma série de significativas mudanças no quadro legal desses países, dentre as quais, importa destacar a substituição do sistema majoritário pelo sistema proporcional, 
com lista fechada e pré-ordenada ${ }^{3}$. O objetivo dessas mudanças jurídicas foi justamente impedir que os partidos socialistas ascendentes fossem favorecidos pelos efeitos mecânicos da reunião de um sistema majoritário ao ingresso (formal) das massas no campo político, por meio do reconhecimento do sufrágio universal. Um importante reflexo dessas modificações no quadro legal eleitoral - sobretudo pela adoção de listas fechadas pré-ordenadas - foi o fortalecimento das lideranças partidárias, que passam a ter o poder de decidir quem pode ser candidato, além de poder definir a sua posição na lista da legenda. A incapacidade de Michels em verificar a limitação temporal de seu esquema teórico comprometeria, assim, a pretensão de universalizar a lei de ferro da oligarquia.

Ainda, é preciso destacar uma crítica secundária à perspectiva micheliana que assume importância na presente análise. No plano de fundo da construção de Michels está presente a premissa de que as massas sociais seriam "formalmente incompetentes, propensas à veneração e dependentes psicologicamente de seus chefes" (MICHELS, 1982, p.53). De modo bastante claro, o domínio exercido pelos líderes partidários sobre as massas seria de soma-zero. Nesse ponto em particular aponta-se um equívoco na perspectiva micheliana, já que o envolvimento do indivíduo com a organização partidária é de natureza voluntária, ou seja, é uma relação onde a lealdade do sujeito precisa ser conquistada pelo partido político, que precisa orientar suas estratégias tendo sempre em seu horizonte a possibilidade (ou o risco) de evasão. Assim, diante da necessidade de se manter na disputa política, a liderança dos partidos políticos estaria fadada a dialogar (distribuir incentivos) com as massas ${ }^{4}$.

\footnotetext{
3 "O progressivo enfranchisement eleitoral, seguido pela ascensão de partidos socialistas termina por tornar disfuncionais os diferentes procedimentos de voto majoritário, até então exclusivos como mecanismo de conversão de sufrágios em cadeiras parlamentares. Em seu lugar, são introduzidas mudanças baseadas em fórmula proporcional, acompanhada na maioria dos casos por procedimentos de ordenamento prévio de candidatos partidários, conhecidos como listas fechadas: assim, apenas quatro anos separam na Bélgica a adoção de sufrágio universal masculino (1885) e a reforma para representação proporcional com listas fechadas (1889). Na Suécia, foram necessários 20 anos entre o alargamento do sufrágio (1889) e o voto em listas partidárias proporcionais (1909). Um pouco mais tardias foram as mudanças de regras eleitorais em direção ao voto proporcional com listas pré-ordenadas na Áustria (1918), Alemanha (1919), França (1919), Dinamarca (1920) e Noruega (1921). Paralelamente, Finlândia (1906), Holanda (1918), Itália (1919) e Irlanda (1922) também substituem o voto majoritário por fórmula proporcional, variando, entretanto, no que diz respeito ao procedimento de alocação das cadeiras partidárias entre seus candidatos. Nesse contexto, o Reino Unido permaneceu como exceção, ao preservar seu modelo de first-past-the-post em distritos uninominais"(MARENCO; NOLL, 2012, p.67).

4 “A suposição implícita aqui é que a competição política em condições de equilíbrio e incerteza provoca dispersão de recursos estratégicos e redução nas assimetrias entre dirigentes e seguidores, ou, ao menos, maiores responsividade e potencial de responsabilização de representantes por seus representados. Sob coordenadas de (i) incremento na competição eleitoral, (ii) mudanças sociais e demográficas - com mobilidade social e escolarização em maiores escalas - e (iii) deslocamento na oferta de capital eleitoral para fora dos partidos (subvenções estatais, profissionalização de campanhas eleitorais e voto retrospectivo), até que ponto a lei de ferro das oligarquias não teria ultrapassado seu prazo de validade?"(MARENCO; NOLL, 2012, p.71).
} 
Um outro viés crítico analisa a crise dos partidos políticos por uma perspectiva diferente - indicando que a inflexão vivenciada na Europa na primeira metade do século XX está diretamente vinculada com uma mudança paradigmática em relação ao papel desempenhado pela estrutura partidária, que deixa de ser o intermediário entre sociedade e Estado - na medida em que este (o Estado) passa a intermediar as relações entre sociedade e partido. Nesse sentido, o movimento de afastamento dos partidos para com a sociedade civil se dá paralelemente a sua aproximação com o Estado - de tal modo que a sua função representativa perde espaço para a função governativa ${ }^{5}$. A busca por alianças capazes de instrumentalizar objetivos governativos aproxima os partidos políticos em termos de ação política e tem como efeito reflexo a corrosão dos projetos ideológicos ${ }^{6}$. Perante o esfacelamento das identidades partidárias e as transformações ao nível das funções, dos modos de organização e a apresentação dos partidos políticos, os eleitores têm cada vez mais dificuldades em percebê-los como representantes dos seus interesses - circunstância em que a crise de representatividade dos partidos políticos se alastra no núcleo do sistema político.

A partir da recuperação dos debates teóricos desenvolvidos no âmbito da Ciência Política a respeito do fenômeno partidário, é possível extrair três advertências importantes aos pesquisadores que tenham como objeto os partidos políticos no Brasil. A primeira advertência está vinculada ao "preconceito sociológico" - isto é - o raciocínio segundo o qual o partido reproduz mecanicamente as desigualdades sociais existentes em determinada comunidade. Além de não refletirem mecanicamente - nem na sua organização nem na sua política - o sistema de desigualdades sociais, produz (antes de mais nada) desigualdades no seu próprio anterior. Nesse particular, a organização partidária produz - desde a sua própria estruturação -

\footnotetext{
5 "Por outras palavras, assim como os partidos mudaram da sociedade para o Estado, as funções que estes desempenham, e se espera que desempenhem, mudaram de uma acção principalmente representativa para uma acção principalmente governativa. Esta mudança enfatiza também um aspecto importante relativo ao suposto 'declínio dos partidos': de facto, os partidos enquanto tais não declinaram, mas modificaram-se e encontram-se hoje cada vez mais implantados nas instituições. Por outro lado, parece cada vez mais evidente a ocorrência de um acentuado declínio das organizações partidárias - pelo menos quando avaliadas em termos de simples dimensão, penetração social e relevância" (MAIR, 2003, p.285).

6 "Logo depois da Segunda Guerra Mundial, o partido burguês, do velho estilo da representação individual, tornou-se exceção. Enquanto alguns exemplares da espécie ainda sobrevivem, a natureza dos sistemas partidários, não obstante, já não é mais determinada por eles. Do mesmo modo, o partido da integração das massas, produto de uma era na qual havia uma rígida linha divisória entre as classes e estruturas de clivagens mais marcadamente protuberantes, está se transformando num partido popular catch-all.29 Abandonando seus esforços antes voltados para o enquadramento intelectual e moral das massas, esse partido está se concentrando mais completamente no cenário eleitoral, na tentativa de trocar a efetividade do debate mais aprofundado por uma audiência mais ampla e pelo sucesso eleitoral mais imediato. Essa tarefa política mais estreita e esse objetivo eleitoral imediato diferem agudamente daquelas preocupações anteriores mais abrangentes; hoje tais preocupações são vistas como contraproducentes porque afastam segmentos de uma clientela potencialmente mais nacional" (KIRCHHEIMER, 2012, p.362-363).
} 
relações complexas de desigualdade entre militantes, apoiadores e representantes (as chamadas "desigualdades organizativas"). A segunda advertência diz respeito à superação do "preconceito teleológico", ou seja, a noção de que os objetivos dos partidos políticos podem ser predeterminados a priori, antes da avaliação da dinâmica política a ser enfrentada pela organização partidária. Desse modo, os partidos políticos passam a se distinguir das demais organizações sociais pelo ambiente específico no qual desempenha uma atividade específica, complexa e que extrapola os limites da representação política. Por fim, a terceira advertência associa-se com a necessidade de perceber o sistema político-partidário brasileiro como resultado da ação do próprio Estado - e não do movimento da sociedade civil organizada.

A constatação de que, no caso brasileiro, a existência de uma estrutura estatal centralizada (no Império, inicialmente, e na República, a posteriori) antes do surgimento do sistema partidário constitui uma relevante dificuldade a sua institucionalização e um verdadeiro estímulo à política clientelista. Nesse sentido, a título de exemplificação, importa destacar que o sistema político-partidário que emergiu após o desmantelamento do Estado Novo em 1945 foi estruturado a partir do planejamento de setores políticos diretamente envolvidos na condução da ditadura de Vargas - e a criação do Partido Social Democrático para dar sobrevida política aos interventores nomeados durante o referido regime de exceção revela de modo claro a instrumentalização da institucionalidade político-partidária. A mesma lógica repercute no período do rompimento democrático experimentado em 1964, quando a partir da instituição do sistema bipartidário na prática política brasileira os limites da atuação do partido de oposição eram constantemente contornados por atos de exceção. A fragilidade da noção de pluripartidarismo na história brasileira até a década de 1980 torna inviável a compreensão das estruturas partidárias enquanto organizações suficientemente autônomas na condução de práticas políticas destinadas a realizar projetos politicamente coerentes com uma ou outra ideologia em particular.

$\mathrm{Na}$ sequência, avaliaremos a coerência teórica de uma proposta concreta para o enfrentamento da crise de representatividade por que passam as organizações partidárias: a implementação, no sistema político-partidário brasileiro, da "cláusula de barreira". A elaboração de um panorama histórico que evidencie a trajetória dessa espécie de mecanismo de contenção na realidade brasileira tem como objetivo conferir ao leitor o manuseio das ferramentas necessárias a uma avaliação crítica do projeto de emenda à Constituição apresentado ao Senado Federal em 2016, objeto do presente estudo em sua derradeira seção. 


\section{3. "CLÁUSULA DE BARREIRA" NA HISTÓRIA DO SISTEMA POLÍtiCO BRASILEIRO: DO CÓDIGO ELEITORAL DE 1950 À PEC36/2016}

A noção de que o ordenamento jurídico deve impor às organizações partidárias limitação objetiva, isto é, estabelecer condicionamento para a concessão de reconhecimento e de capacidade de atuação parlamentar surgiu no contexto político alemão após a segunda grande guerra, com o objetivo de forçar a moderação dos discursos dos partidos extremistas (tanto à direita, quanto à esquerda). A cláusula de barreira (ou cláusula de desempenho) é uma limitação à participação no campo político-partidário, isto é, é o condicionamento da participação ou até mesmo a existência dos partidos no sistema político à obtenção de uma quantidade mínima de votos nas eleições, distribuídas em conformidade com os critérios estabelecidos pelo legislador no território nacional. Referido mecanismo suscita o debate entre aqueles que vislumbram na sua essência uma pretensão autoritária de esmagamento dos setores sociais minoritários, de um lado, e aqueles que apostam no seu potencial de combate à pulverização dos partidos políticos nas instâncias deliberativas que contribui para o distanciamento entre a população e seus representantes e, ainda, cria sérios problemas para a governabilidade em regimes presidencialistas.

$\mathrm{O}$ primeiro registro de um instrumento nesses contornos, na realidade brasileira, data de meados do século XX. O Código Eleitoral de 1950 previa que o partido que não conseguisse eleger pelo menos um representante para o Congresso Nacional ou que não obtivesse a adesão de pelo menos cinquenta mil votos teria seu registro cancelado perante a Justiça Eleitoral $^{7}$. Considerando as exigências impostas aos partidos políticos, é possível afirmar um menor grau de severidade da exigência legal - que seria significativamente transformado nas ocasiões sucessivas de emergência desse tipo de instrumento de limitação da participação partidária.

A crise política experimentada na década de 1960 e o efetivo rompimento institucional ocorrido em março de 1964 constituem o prelúdio de importantes modificações no sistema político-partidário brasileiro. É necessário destacar que a deposição do Presidente João Goulart e a publicação do primeiro Ato Institucional em abril de 1964 não resultaram em um

\footnotetext{
7 “Art. 148. Ainda se cancelará o registro do partido que, no seu programa ou ação, vier a contrariar o regime democrático baseado na pluralidade dos partidos e na garantia dos direitos fundamentais do homem.

Parágrafo único. Terá, por igual, cancelado o seu registro o partido que em eleições gerais não satisfizer uma destas duas condições: eleger, pelo menos, um representante no Congresso Nacional ou alcançar, em todo o país, cinqüenta mil votos sob legenda." Disponível em: http://www.planalto.gov.br/ccivil_03/leis/19501969/L1164.htm. Acesso em 25/09/2016.
} 
imediato rompimento com o sistema eleitoral e partidário elaborado entre 1945 e 1960, o que pode ser verificado a partir da manutenção do funcionamento dos partidos políticos existentes até então (com destaques aos três principais, quais sejam, a UDN, o PSD e o PTB). O resultado das eleições estaduais de 1965 (com significativa vitória da aliança PSD-PTB) fez o regime civil-militar instalado em 1964 perceber na continuidade do sistema partidário pré-64 uma ameaça à implantação dos objetivos da "revolução". Em razão disso, o Ato Institucional $\mathrm{n} .2^{8}$ - dentre outras medidas - extinguiu as organizações partidárias existentes e o Ato Complementar n.4, na sequência, estabeleceu os pré-requisitos exigidos à criação das novas organizações que exerceriam as "funções dos partidos políticos" ". A pretensão de concentrar a oposição (resultante das cassações promovidas pelos atos institucionais) ao regime em um único corpo revelou-se pelos requisitos exigidos à criação dos partidos.

No contexto da segunda metade da década de 1960, quando os atos institucionais e complementares já haviam modificado de modo substancial o quadro normativo em geral, emergiu a necessidade de recomposição de um texto constitucional coerente com referidas alterações. Assim, em meio à constante ameaça dos atos de exceção, o Congresso Nacional foi convocado extraordinariamente em dezembro de 1966 pelo General Castelo Branco para homologar o projeto constitucional do Executivo. A Constituição de 1967, assumindo compromisso com o discurso do movimento civil-militar de 1964, implementou - pela primeira vez em nível constitucional - uma cláusula de barreira à existência de partidos políticos, na medida em que exigia a legenda obtivesse o apoio de dez por cento do eleitorado que houvesse votado na última eleição geral, distribuídos em dois terços dos Estados federados, com o mínimo de sete por cento em cada um deles, além de dez por cento de deputados em pelo menos um terço dos Estados e dez por cento de senadores ${ }^{10}$.

\footnotetext{
8 "Art. 18 - Ficam extintos os atuais Partidos Políticos e cancelados os respectivos registros." Disponível em: http://www.planalto.gov.br/ccivil_03/AIT/ait-02-65.htm. Acesso em 25/09/2016.

9 "Art. $1^{\circ}$ Aos membros efetivos do Congresso Nacional, em número não inferior a 120 deputados e 20 senadores, caberá a iniciativa de promover a criação, dentro do prazo de 45 dias, de organizações que terão, nos termos do presente Ato, atribuições de partidos políticos enquanto estes não se constituírem." Disponível em: http://www.planalto.gov.br/ccivil_03/ACP/acp-004-65.htm. Acesso em 25/09/2016.

${ }^{10}$ Art 149 - A organização, o funcionamento e a extinção dos Partidos Políticos serão regulados em lei federal, observados os seguintes princípios:

I - regime representativo e democrático, baseado na pluralidade de Partidos e na garantia dos direitos fundamentais do homem;

II - personalidade jurídica, mediante registro dos estatutos;

III - atuação permanente, dentro de programa aprovado pelo Tribunal Superior Eleitoral, e sem vinculação, de qualquer natureza, com a ação de Governos, entidades ou Partidos estrangeiros;

IV - fiscalização financeira;

V - disciplina partidária;

VI - âmbito nacional, sem prejuízo dag funções deliberativas dos Diretórios locais;
} 
As dificuldades enfrentadas pela oposição ao regime (Movimento Democrático Brasileiro, doravante MDB) em termos de organização e manutenção das estruturas partidárias no âmbito local impuseram a modificação das regras eleitorais. Não era do interesse do regime autoritário a extinção do partido de oposição, dado que sua existência conferia aparência de legalidade à ordem vigente. Desse modo, a Emenda Constitucional n. 1 de 1969 retoma a questão e flexibiliza a limitação às organizações partidárias, fixando que estas deveriam obter cinco por cento do eleitorado que houvesse votado na última eleição geral para a Câmara dos Deputados, distribuídos pelo menos em sete Estados federados, com o mínimo de sete por cento em cada um deles ${ }^{11}$.

A partir de 1974, quando o Movimento Democrático Brasileiro (MDB) alcança importante capacidade de se distinguir do partido de apoio ao governo (Aliança Renovadora Nacional, ARENA) e se articula na ampliação de suas bases sociais - o que ocorre paralelamente ao sucesso eleitoral no mesmo ano - inverte a lógica do sistema. Estando reunida de forma coordenada, o partido de oposição (MDB) assume a função de barrar projetos legislativos enviados pelo Executivo ao Congresso, o que gera um tensionamento expressivo entre os dois poderes. Nesse compasso, diante da extrapolação da atuação do MDB para além dos limites previamente desenhados pelo regime autoritário (o que pode se verificar

VII - exigência de dez por cento do eleitorado que haja votado na última eleição geral para a Câmara dos Deputados, distribuídos em dois terços dos Estados, com o mínimo de sete por cento em cada um deles, bem assim dez por cento de Deputados, em, pelo menos, um terço dos Estados, e dez por cento de Senadores;

VIII - proibição de coligações partidárias (Grifo nosso). Disponível em: http://www.planalto.gov.br/ccivil 03/Constituicao/Constituicao67.htm. Acesso em 25/09/2016.

${ }_{11}$ Art. 152. A organização, o funcionamento e a extinção dos partidos políticos serão regulados em lei federal, observados os seguintes princípios:

I - regime representativo e democrático, baseado na pluralidade de partidos e na garantia dos direitos fundamentais do homem;

II - personalidade jurídica, mediante registro dos estatutos;

III - atuação permanente, dentro de programa aprovado pelo Tribunal Superior Eleitoral, e sem vinculação, de qualquer natureza, com a ação de governos, entidades ou partidos estrangeiros;

IV - fiscalização financeira;

V - disciplina partidária;

VI - âmbito nacional, sem prejuízo das funções deliberativas dos diretórios locais;

VII - exigência de cinco por cento do eleitorado que haja votado na última eleição geral para a Câmara dos Deputados, distribuídos, pelo menos, em sete Estados, com o mínimo de sete por cento em cada um dêles;

VIII - proibição de coligações partidárias.

Parágrafo único. Perderá o mandato no Senado Federal, na Câmara dos Deputados, nas Assembléias Legislativas e nas Câmara Municipais quem, por atitudes ou pelo voto, se opuser às diretrizes legitimamente estabelecidas pelos órgãos de direção partidária ou deixar o partido sob cuja legenda foi eleito. A perda do mandato será decretada pela Justiça Eleitoral, mediante representação do partido, assegurado o direito de ampla defesa (Grifo nosso). Disponível em: http://www.planalto.gov.br/ccivil_03/Constituicao/Emendas/Emc_anterior1988/emc01-69.htm. Acesso em 25/09/2016. 
a partir do crescimento do apoio da sociedade civil ao MDB), a reforma do sistema políticopartidário aponta novamente no cenário como medida necessária. Assim, em outubro de 1978 a Emenda Constitucional n. 11 flexibiliza ainda mais a cláusula de barreira contida no sistema, exigindo a obtenção de cinco por cento do eleitorado que houvesse votado para a Câmara dos Deputados, distribuídos em pelo menos nove Estados, sendo que em cada um deles deveria se atingir no mínimo três por cento ${ }^{12}$.

Finalmente, para encerrar a análise dessa experiência inaugurada pela Constituição de 1967 (objeto de diversas modificações, como expusemos até o presente momento), é preciso referir a disposição incluída pela Emenda Constitucional n.25, de 1985, que fixou a necessária obtenção do apoio de três por cento do eleitorado das eleições gerais, distribuídos os votos em pelo menos cinco Estados federados, com o mínimo de dois por cento em cada um deles para que o partido político pudesse ter direito à representação no Congresso Nacional ${ }^{13}$. A análise

12 “Art. 152 - A organização e o funcionamento dos partidos políticos, de acordo com o disposto neste artigo, serão regulados em lei federal.

$\S 1^{\circ}$ - Na organização dos partidos políticos serão observados os seguintes princípios:

I - regime representativo e democrático, baseado na pluralidade dos partidos e garantia dos direitos humanos fundamentais;

II - personalidade jurídica mediante registro dos estatutos;

III - inexistência de vínculo, de qualquer natureza, com a ação de governos, entidades ou partidos estrangeiros;

IV - Âmbito nacional, sem prejuízo das funções deliberativas dos órgãos regionais ou municipais.

$\$ 2^{\circ}$ - O funcionamento dos partidos políticos deverá atender às seguintes exigências:

I - filiação ao partido de, pelo menos, $10 \%$ (dez por cento) de representantes na Câmara dos Deputados e no Senado Federal que tenham, como fundadores, assinado seus atos constitutivos; ou

II - apoio, expresso em votos, de $5 \%$ (cinco por cento) do eleitorado, que haja votado na última eleição geral para a Câmara dos Deputados, distribuídos, pelo menos, por nove Estados, com o mínimo de 3\% (três por cento) em cada um deles;

III - atuação permanente, dentro do programa aprovado pelo tribunal superior Eleitoral;

IV - disciplina partidária;

$\mathrm{V}$ - fiscalização financeira.

$\S 3^{\circ}$ - Não terá direito a representação o partido que obtiver votações inferiores aos percentuais fixados no item II do parágrafo anterior, hipótese em que serão consideradas nulas.

$\S 4^{\circ}$ - A extinção dos partidos políticos dar-se-á na forma e nos casos estabelecidos em lei.

$\S 5^{\circ}$ - Perderá o mandato no senado Federal, na Câmara dos Deputados, nas Assembléias Legislativas e nas Câmaras Municipais quem, por atitude ou pelo voto, se opuser às diretrizes legitimamente estabelecidas pelos órgãos de direção partidária ou deixar o partido sob cuja rege for eleito, salvo se para participar, como fundador, da constituição de novo partido.

$\S 6^{\circ}$ - A perda do mandato, nos casos previstos no parágrafo anterior, será decretada pala Justiça Eleitoral, mediante representação do partido, assegurado o direito de ampla defesa" (Grifo nosso). Disponível em: http://www.planalto.gov.br/ccivil_03/Constituicao/Emendas/Emc_anterior1988/emc11-78.htm. Acesso em 25/09/2016.

13 “Art. 152. É livre a criação de Partidos Políticos. Sua organização e funcionamento resguardarão a Soberania Nacional, o regime democrático, o pluralismo partidário e os direitos fundamentais da pessoa humana, observados os seguintes princípios:

I - é assegurado ao cidadão o direito de associar-se livremente a Partido Político;

Il - é vedada a utilização pelos Partidos Políticos de organização paramilitar;

III - é proibida a subordinação dos Partidos Políticos a entidade ou Governo estrangeiros;

IV - o Partido Político adquirirá personalidade jurídica mediante registro dos seus Estatutos no Tribunal Superior Eleitoral; 
dos dispositivos previstos no texto constitucional de 1967, sucessivamente modificado no sentido da flexibilização das exigências impostas aos partidos políticos, é importante para esclarecer a preocupação do constituinte de 1987 com o grau de autonomia entregue às organizações partidárias projetadas para atuarem no âmbito do Estado Democrático de Direito fundado pela nova Constituição.

A Constituição Federal de 1988 rompe com o paradigma anterior no sentido de conceder aos partidos políticos ampla autonomia no que diz respeito a sua criação, fusão, incorporação e extinção, resguardados a soberania nacional, o regime democrático, o pluripartidarismo e os direitos fundamentais da pessoa humana. Não há qualquer referência ao condicionamento da atuação (ou mesmo da existência) das organizações partidárias ao desempenho obtido pelas mesmas nas eleições. Nesse sistema, a implementação de uma cláusula de barreira foi suscitada principalmente em duas ocasiões: a primeira na oportunidade do processo de revisão constitucional ocorrido em 1993, quando o Deputado Federal Nelson Jobim elaborou parecer no sentido da adoção de referida cláusula; e a segunda com a vigência da lei n. 9.096/1995 - a "Lei dos Partidos Políticos", que efetivamente impunha uma cláusula de barreira em seu artigo $13^{14}$. O fato é que, diante da controvérsia ensejada pela segunda, o Supremo Tribunal Federal foi provocado a se manifestar a respeito da constitucionalidade de referido dispositivo, nas Ações Diretas de Inconstitucionalidade n. 1351-3(DF) e 1354-8(DF). Em dezembro de 2006, a Suprema Corte brasileira decidiu pela

V - a atuação dos Partidos Políticos deverá ser permanente e de âmbito nacional, sem prejuízo das funções deliberativas dos órgãos estaduais e municipais.

$\S 1^{\circ}$ Não terá direito a representação no Senado Federal e na Câmara dos Deputados o Partido que não obtiver o apoio, expresso em votos, de $3 \%$ (três por cento) do eleitorado, apurados em eleição geral para a Câmara dos Deputados e distribuídos em, pelo menos, 5 (cinco) Estados, com o mínimo de $2 \%$ (dois por cento) do eleitorado de cada um deles.

$\S 2^{\circ}$ Os eleitos por Partidos que não obtiverem os percentuais exigidos pelo parágrafo anterior terão seus mandatos preservados, desde que optem, no prazo de 60 (sessenta) dias, por qualquer dos Partidos remanescentes.

$\S 3^{\circ}$ Resguardados os princípios previstos no "caput" e itens deste artigo, lei federal estabelecerá normas sobre a criação, fusão, incorporação, extinção e fiscalização financeira dos Partidos Políticos e poderá dispor sobre regras gerais para a sua organização e funcionamento" (Grifo nosso). Disponível em: http://www.planalto.gov.br/ccivil_03/Constituicao/Emendas/Emc_anterior1988/emc25-85.htm. Acesso em 25/09/2016.

${ }^{14}$ "Tem direito a funcionamento parlamentar, em todas as Casas Legislativas para as quais tenha elegido representante, o partido que, em cada eleição para a Câmara dos Deputados obtenha o apoio de, no mínimo, cinco por cento dos votos apurados, não computados os brancos e os nulos, distribuídos em, pelo menos, um terço dos Estados, com um mínimo de dois por cento do total de cada um deles". Disponível em: http://www.planalto.gov.br/ccivil 03/leis/L9096.htm. Acesso em 26/09/2016. 
inconstitucionalidade da clausula de barreira introduzida pela Lei dos Partidos Políticos (lei n.9.096) $)^{15}$.

Desde a publicação do acórdão do Egrégio Tribunal, novas propostas de modificação do sistema por meio da inclusão de cláusula de barreira via emenda à constituição repercutiram nas instâncias legislativas - sem que qualquer delas tenha, até o presente momento, completado o ciclo do procedimento legislativo. A avaliação de cada uma dessas propostas extrapola os limites do presente trabalho, que tem como foco o estudo pontual da PEC36/2016, que emerge no cenário brasileiro como resposta à crise de representatividade que atinge as instituições estatais no território nacional.

A PEC36/2016 propõe a implementação de uma cláusula de barreira pela qual o ordenamento jurídico passaria a classificar os partidos políticos em duas categorias: aqueles com funcionamento parlamentar (atendidos os condicionamentos da cláusula de barreira) e aqueles sem funcionamento parlamentar (caso contrário). A pretensão é a de que a partir das eleições de 2018, teriam status de partidos com funcionamento parlamentar aqueles que obtivessem um mínimo de dois por cento dos votos válidos apurados nacionalmente (critério 1), distribuídos em pelos menos, quatorze unidades da Federação (critério 2), com um mínimo de dois por cento dos votos válidos em cada uma delas (critério3) - sendo que a partir das eleições de 2022, os critérios seriam ligeiramente mais rígidos: a obtenção de um mínimo de três por cento dos votos válidos apurados nacionalmente (critério 1), distribuídos em, pelo menos, quatorze unidades da Federação (critério 2), com um mínimo de dois por cento dos votos válidos em cada uma delas (critério 3) ${ }^{16}$. A promessa da PEC36/2016 é preservar a representação política e respeitar a escolha do eleitor (reservando espaço para os parlamentares eleitos pelos partidos políticos), ao mesmo tempo em que combate a pulverização (ou fragmentação) dos partidos políticos no Congresso Nacional. O apelo presente na proposta diz respeito à imprescindibilidade da adoção de mecanismos capazes de resolver os problemas da governabilidade nos sistemas presidencialistas de coalisão. Como se pode verificar, o pressuposto básico da PEC16 é o de que o "pluralismo não deve servir como subterfúgio da desordem e da inexistência de um mínimo de ação política” (KNEIPP, 2002, p.25).

\footnotetext{
15 "Surge conflitante com a Constituição Federal lei que, em face da gradação de votos obtidos por partido político, afasta o funcionamento parlamentar e reduz, substancialmente, o tempo de propaganda partidária gratuita e a participação no rateio do Fundo Partidário". SUPREMO TRIBUNAL FEDERAL. ADIN 1351-3-DF. Rel. Min. Marco Aurélio. Julgado em 7/12/2006. Disponível em: http://www.stf.jus.br/portal/processo/verProcessoAndamento.asp. Acesso em 20/09/2016.

${ }^{16}$ Disponível em: http://www12.senado.leg.br/hpsenado. Acesso em 25/09/2016.
} 
A análise crítica da proposta acima exposta pode ser realizada a partir de dois pontos centrais: o necessário respeito ao princípio basilar que está no âmago dos regimes democráticos (qual seja, o da garantia da participação das minorias) e, ainda, a preservação de uma relação coerente entre fins e meios (a cláusula de barreira tem o potencial de reduzir a fragmentação partidária?). É justamente para esse enfrentamento que o presente estudo se dirige na sequência.

Inicialmente, importa registrar que a cláusula de barreira que condiciona o funcionamento parlamentar do partido político ao seu desempenho nas urnas não se coaduna com o sistema pluripartidário fundado na Constituição Federal de 1988, sobretudo porque representa verdadeiro afastamento das minorias do processo político. Aliás, esse argumento foi o que estruturou o precedente da Suprema Corte que fulminou a cláusula de barreira inserida no ordenamento jurídico brasileiro pela Lei n. 9.096/95. Na justificativa da PEC36/2016 defendeu-se que o mecanismo contido na pretendida reforma distingue-se significativamente daquela afastada pela cúpula do Poder Judiciário pátrio, na medida em que estabelece - para fins de estabelecimento parlamentar - distinções entre os partidos que obtiverem o desempenho de dois por cento (nas eleições de 2018) ou de três por cento (nas eleições de 2022) dos votos válidos e aqueles que não alcançarem essa quantidade de votos. A defesa do referido projeto salienta o fato de que, pela reforma sugerida, restaria assegurado o direito do parlamentar filiado a um partido que não alcançou o patamar eleitoral imposto pela PEC de praticar todos os atos inerentes ao exercício, preservando, portanto, a representação política.

A vantagem em alcançar o patamar eleitoral e se credenciar enquanto "partido político com funcionamento parlamentar" (uma espécie de partido político de "primeira classe") seria ter assegurado o direito à proposição de ações de controle de constitucionalidade, à estrutura própria e funcional nas casas legislativas, à participação da distribuição dos recursos do fundo partidário e ao acesso gratuito ao rádio e à televisão, na forma da lei. É evidente que a perda das referidas prerrogativas (meios de efetiva atuação partidária) não exclui, por si mesmo, os pequenos partidos do sistema - mas reduz de modo drástico o potencial alcance de seus projetos, representando verdadeira limitação à representatividade político-partidária das organizações partidárias minoritárias. É o retrato de um modelo que não exclui diretamente o partido das minorias, mas restringe-lhe de modo significativo a capacidade de ampliar suas bases (vide a importância do fundo partidário para o financiamento da estrutura dos partidos). 
Por outro lado, é importante pontuar que a crença no potencial da cláusula de barreira em reduzir a fragmentação política brasileira está alicerçada nos dois preconceitos sublinhados na primeira parte do presente estudo: o sociológico e o teleológico. A perspectiva que sustenta a PEC36/2016 parece ignorar o fato de que os partidos políticos não são estruturas homogêneas ou monolíticas, e que as dinâmicas havidas em seu interior resultam em mais desigualdades (desigualdades organizativas). A tendência de perceber as organizações partidárias enquanto peças que se movem em um tabuleiro conhecido de acordo com uma ideologia pré-definida não passa de um exercício de pura imaginação, e a partir da observação das dinâmicas estabelecidas pelos mais variados partidos políticos no contexto brasileiro a sua defesa só se explica por duas hipóteses: ignorância ou má-intenção.

\section{CONSIDERAÇÕES FINAIS}

O diálogo entre o direito e a ciência política é fundamental para a compreensão e o diagnóstico da crise de representatividade enfrentada pelo sistema político brasileiro na atualidade. Revela-se, em boa medida, indispensável a apropriação dos debates teóricos no campo das organizações partidárias para a problematização dos mecanismos apontados como potenciais alternativas às crises - como é o caso da cláusula de barreira, analisada no presente estudo.

A avaliação da PEC36/2016, em tramitação no Senado Federal, revela que a alternativa sugerida é a implementação de condicionamentos com menor rigor em relação às anteriormente propostas ou praticadas no ordenamento jurídico pátrio. Em que pese a flexibilização desses critérios (sobretudo quando ao número de votos válidos exigidos nacionalmente), a avaliação do presente trabalho conduz à duas principais conclusões: a) a proposta é materialmente inconstitucional, na medida em que estabelece uma categoria de "partido político de segunda classe", com direitos partidários restringidos, em desconformidade com o pluripartidarismo afirmado no texto constitucional de 1988; e b) o projeto é resultado de um raciocínio viciado pelos preconceitos (sociológico e teleológico) identificados pelos cientistas políticos, na medida em que vislumbram um partido imaginário, desconectado com a realidade partidária no Brasil. 


\section{REFERÊNCIAS BIBLIOGRÁFICAS}

BEYME, Klaus Von. Los partidos políticos em las democracias occidentales. Madrid: Centro de Investigaciones Sociológicas, 1986.

DUVERGER, Maurice. Los partidos políticos. Ciudad de Mexico: FCE, 1957.

EPSTEIN, Leon. Political Parties in Western Democracies. Nueva York: Praeger, 1967.

GONZÁLEZ, Víctor Hugo Martínez. Partidos políticos: un ejercicio de clasificación teórica . In: Revista Perfiles Latinoamericanos, n.33, jan-jun, 2009.

KIRCHHEIMER, Otto. As transformações dos sistemas partidários da Europa Ocidental. In: Revista Brasileira de Ciência Política, Brasília, n.7, jan-abr, 2012. p.349-385.

KNEIPP, Bruno Burgarelli Albergaria. A pluralidade de partidos políticos. Belo Horizonte: Del Rey, 2002.

KREHBIEL, Keith. Where is the party?. In: British Journal of Political Science, London, Vol.23, N.2, p.235-266.

LAPALOMBARA, Joseph; WEINER, Myron. Political parties and political development. Princeton: University Press, 1966.

LAWSON, Kay. The Comparative Study of Political Parties. Nueva York: St. Martin's Press, 1976

MAIR, Peter. Os partidos políticos e a democracia. In: Análise Social, vol. XXXVIII, n.167, 2003, p.277-293.

MARENCO, André; NOLL, Maria Izabel. As décadas de Michels: marcos contextuais e prazo de validade para a "Lei de Ferro". In: Revista Sociologia Política, Curitiba,v.20, n.44, 2012, p.63-72.

MICHELS, Robert. Los partidos políticos. Buenos Aires: Amorrortu, 1962.

PANEBIANCO, Angelo. Modelos de partido. Madrid: Alianza, 1990.

SARTORI, Giovanni. Partidos y sistemas de partidos. Madrid: Alianza, 1980.

WEBER, Max. El político y el científico. Madrid: Alianza, 1967. 